\title{
CONTRIBUIÇÕES TEÓRICAS ACERCA DA CONSTITUIÇÃO DA HOMOFOBIA*
}

\author{
Theoric contributions about constitution of homophobia
}

\begin{abstract}
RESUMo À luz do referencial teórico do materialismo histórico e dialético de Karl Marx, que tem como pressuposto a centralidade da história, o presente artigo se propõe a atingir dois objetivos: compreender e analisar como alguns elementos históricos e culturais constitutivos da homofobia contribuem para a naturalização de atitudes homofóbicas e encontrar pistas para o enfrentamento da violência e da discriminação contra quaisquer manifestações não heterossexuais. Percorremos alguns aspectos da história da família, da propriedade privada, da igreja e da sexualidade. Em seguida, propusemo-nos a refletir acerca dos fatores sociais, culturais e psíquicos que constituem o preconceito, que aparece sempre como uma possibilidade. Os estudos revelaram a) o quanto a convicção na família monogâmica como natural contribuiu para a instalação e para a perpetuação do preconceito sexual; b) como a vontade de saber sobre o sexo normatizou a sexualidade instituindo algumas manifestações como desviantes e anormais e c) o papel do conhecimento para a superação do preconceito e de toda forma de violência.
\end{abstract}

Palavras-chave: Homofobia. Homossexualidade. História. EDUCAÇÃO.

ABSTRACT In light of the theoretical framework of Karl Marx's historical and dialectical materialism, which presupposes the centrality of history, this paper aims two goals: to understand and to analyze how some constitutive historical and cultural elements of homophobia contribute to the naturalization of homophobia and to find clues to combat violence and discrimination against any non-heterosexual expressions attitudes. We have brought some aspects of history of family, of private property, of church and of sexuality. Then we set out to reflect on the social, cultural and psychological factors that make up the prejudice, which always appears as a possibility. Studies revealed a) how much the belief in the monogamous family as the natural form contributed to the installation and to the perpetuation of gender bias; b) how the desire to know about sex has standardized sexuality, instituting some manifestations as deviant and abnormal and c) the role of knowledge to overcome prejudice and every kind of violence.

KEYWORDS: HOMOPHOBIA. HOMOSEXUALITY. HISTORY.

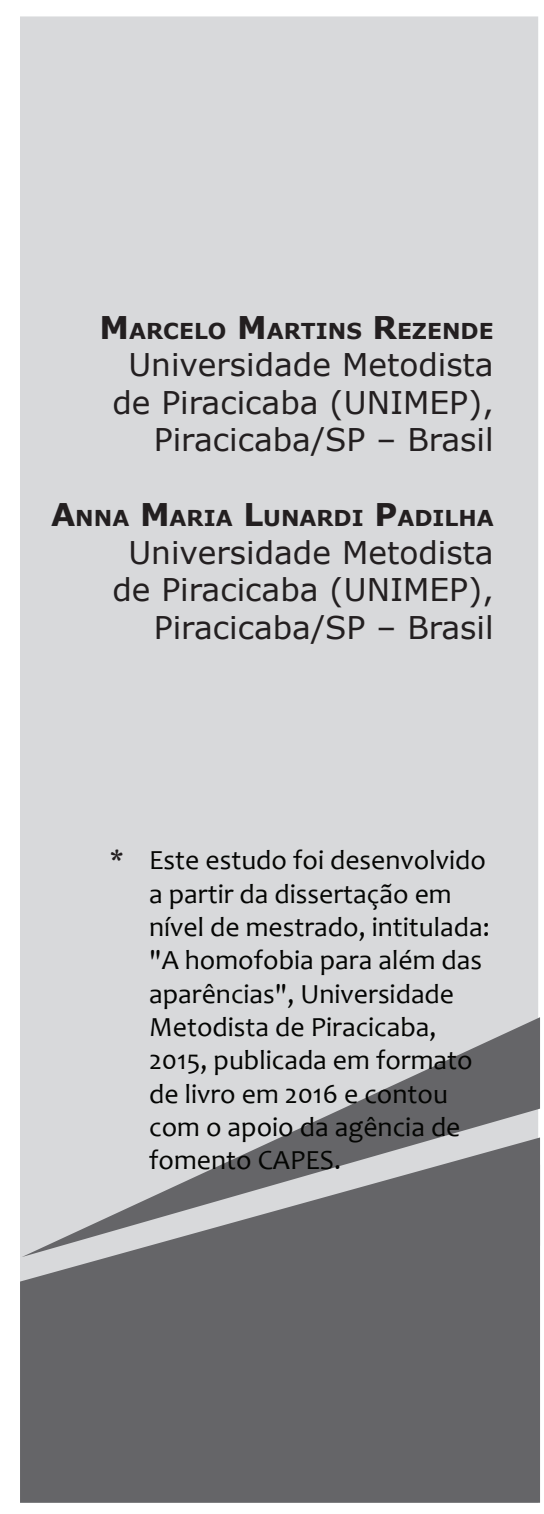




\section{INTRODUÇÃO}

$\mathrm{F}$ atos e informações relacionados à sexualidade e suas manifestações têm sido amplamente veiculados nos diferentes espaços midiáticos, dando-nos, à primeira vista, a impressão de que caminhamos em direção à superação dos preconceitos sexuais. Porém, recentemente, a sociedade brasileira assistiu grupos fundamentalistas, principalmente os religiosos, se levantarem contra as expressões de gêneros contidas no Plano Nacional de Educação, alegando que estariam promovendo a ideologia de gênero nas escolas.

Dinis (2008), em seu artigo Educação, relações de gênero e diversidade sexual, afirma que vivemos um momento histórico em que, apesar de se proclamar uma educação para a diferença ou para a diversidade, há um crescente silenciamento e omissão quando o assunto é relacionado ao combate à homofobia'. Silêncio assumido pelo órgão legislador, que não criminaliza a homofobia, como afirma Dias (2011), mas, em alguma medida, assumido por todos nós, por não nos incomodarmos ou pouco fazermos para a superação do preconceito.

A fim de compreendermos melhor os motivos dessa omissão e, quiçá, conseguirmos rompê-las, estabelecemos dois objetivos para o presente artigo: $1^{\circ}$ ) compreender e analisar como alguns elementos históricos e culturais constitutivos da homofobia contribuem para a naturalização de atitudes homofóbicas e $2^{\circ}$ ) encontrar pistas para o enfrentamento da violência e da discriminação contra quaisquer manifestações não heterossexuais.

Para alcançar esses objetivos, escolhemos como referencial teórico o materialismo histórico e dialético, método de estudo científico utilizado por Karl Marx, que tem como pressuposto a centralidade da história e que se encontra comprometido como a transformação social.

A partir dos pressupostos marxianos, fomos instigados a investigar alguns elementos

Entende-se homofobia como "a atitude de hostilidade contra as/os homossexuais; portanto, homens ou mulheres". (BORRILLO, 2010, p. 13). históricos e culturais constitutivos do preconceito contra homossexuais, buscando fundamentos nos estudos da história da família, da propriedade privada, da igreja e da sexualidade e, em seguida, a pensar o preconceito a partir da estrutura da vida cotidiana e os aspectos subjetivos da constituição do preconceito.

A escolha dos autores como referências para a realização deste estudo, integrantes de diversas matrizes teóricas e envolvendo diferentes áreas do saber, nos parece adequada por ampliar nossa possibilidade de compreender os objetivos aqui propostos.

Crochík nos ensina que "para estudar e entender o preconceito, é necessário recorrer a mais de uma área do saber", pois, sendo um fenômeno psicológico, pode também se desenvolver no processo de socialização do sujeito, variando "historicamente dentro da mesma cultura e em culturas diferentes" 2 .

\section{OS VESTÍGIOS DA HISTÓRIA}

Nos estudos históricos que empreendemos, encontramos algumas pistas acerca dos elementos constitutivos da homofobia. Friedrich Engels (2002), em seu livro A origem da família, da propriedade privada e do Estado, esclarece como se deu o processo histórico da formação da família, que, em alguma medida, contribuiu para uma concepção social na qual se fundam o machismo ${ }^{3}$, o sexismo ${ }^{4}$ e, consequentemente, a homofobia.

Baseado em estudos anteriores, Engels analisa as formas primitivas da família, percorrendo diferentes modos de organização familiar, começando pela família consanguínea, punaluana, sindiásmica até chegar ao modelo de família monogâmica, que sofreu apenas pequenas mudanças até chegar ao padrão que é adotado hoje.

CROCHÍK, 2011, p. 13.

3 De acordo com PINTO, MENEGHEL e MARQUES (2007, p. 239), machismo é o conjunto de atitudes e ideias que considera o sexo masculino superior ao sexo feminino, ou seja, atitudes e ideias que colocam a mulher em uma posição inferior.

4 BORRILLO (2010, p.30) nos ensina que o sexismo é a ordem sexual e a hierarquização das relações das sexualidades, em que o papel atribuído aos homens se sobrepõe ao das mulheres. 
O ocultamento dos traços históricos por parte de instituições responsáveis pela transmissão dos valores morais, culturais e sociais, como a família, a escola, a igreja, deu ao longo do tempo à família monogâmica um aspecto de natural, desconsiderando as outras formas de organização que ocorreram em tempos remotos.

Os estudos acerca da história primitiva revelaram vestígios de um breve estágio de promiscuidade, "[...] correspondente à passagem da animalidade à humanidade" 5 , que se transformou na família consanguínea. $\mathrm{Na}$ família consanguínea, todos eram maridos e mulheres entre si, irmãos e irmãs, e seus vínculos pressupunham uma relação carnal.

Desta primeira organização, surgiu a família punaluana, excluindo as relações sexuais recíprocas entre os pais e os filhos e depois entre irmãos.

Segundo Engels, no grau imediatamente superior de desenvolvimento da família punaluana, encontram-se as famílias sindiásmicas, entendidas como "[...] uniões por pares, de duração mais ou menos longa" e que se reduziu à unidade biatômica: um homem e uma mulher.

$\mathrm{Na}$ organização familiar sindiásmica, a produção baseava-se na economia doméstica do comunismo primitivo e a divisão do trabaIho era espontânea, expandindo-se para a divisão sexual entre o homem e a mulher, conhecida como a primeira divisão social do trabalho? .

Foi um período em que os homens eram responsáveis pela caça, pesca e produção de armas para esses feitos; as mulheres ficavam com o cuidado da casa, da comida e da confecção das roupas. Nessa época foram criadas outras formas de riqueza e houve o desenvolvimento da domesticação de animais, da confecção de artesanato e da fundição de minerais.

As mudanças que ocorreram na organização social favoreceram o surgimento da figura paterna, que passou a ocupar uma posição im-

\footnotetext{
ENGELS, 2002, p. 37.

Idem, p. 47.

A divisão social do trabalho está apresentada no manuscrito A ideologia alemã, redigido em 1845-1846 por Marx e Engels.
}

portante nessa sociedade; aos homens passou a ser dado o direito hereditário paterno, dando início ao modelo de família patriarcal.

Em paralelo à transição da família sindiásmica à família monogâmica, ocorreu na história o que ficou conhecido como a segunda e posteriormente a terceira divisão social do trabalho.

A família monogâmica - com pequenas variações entre as regiões e, conforme ressalva feita por Engels, entre a classe dominante e a classe oprimida - foi se transformando em regra para toda a sociedade. Conforme esclarece o historiador Philippe Ariès, em seu livro História social da criança e da família (1981), o sentimento de família burguesa que constituiu a sociedade do século XVIII modificou-se muito pouco até nossos dias.

Entender o caminho histórico que o modelo familiar que hoje se considera normal percorreu até estabelecer-se é essencial para compreender que os principais traços da família monogâmica, pautados em uma "hierarquia sexual e na naturalização da diferença do sexo masculino e feminino", reforçaram e reforçam os preconceitos, "afetando a vida de todos aqueles" que de algum modo não se enquadram no modelo pré-estabelecido. ${ }^{8}$

Para ampliar a compreensão do que estamos chamando de elementos históricos e culturalmente constitutivos dos preconceitos, utilizamo-nos dos estudos do filósofo e historiador Michael Foucault (1988; 2001). De acordo com esse autor, ao longo de toda a História Ocidental, se construiu um saber sobre o sexo que resultou em uma normatização da sexualidade e que contribuiu para o fortalecimento do preconceito em relação a todos os que desviassem dessa norma.

Foi uma época em que os saberes médico e jurídico obtiveram um enorme poder, investigando a forma de ser e de viver dos sujeitos, examinando suas condutas e enquadrando-as como normais ou patológicas.

Para identificar e controlar os sujeitos considerados desviantes, foram utilizados mecanismos que estavam alicerçados na prá-

\footnotetext{
$8 \quad$ REZENDE, 2015, p. 27.
} 
tica da revelação obrigatória, de modo que, segundo Foucault, "[...] a sexualidade, no Ocidente, não é o que se cala, não é o que se é obrigado a calar, mas é o que se é obrigado a revelar"9.

Aliada à psiquiatria, a estratégia cristã da revelação obrigatória se infiltrou em diferentes espaços sociais, voltando-se para um detaIhado exame do corpo e consequentemente para o controle da sexualidade. Controle que foi marcado pela vontade de saber do século XIX, se constituindo em ciência sobre o sexo.

O saber sobre o sexo "propagou, especulou e investigou sobre as diferentes manifestações sexuais, porém, essas diferentes manifestações não ocuparam os mesmos lugares sociais, as mesmas categorias morais ou o mesmo estatuto de normalidade", atribuído à prática heterossexual. As outras manifestações sexuais, por fugirem de um padrão imposto como normal, passaram a ser "entendidas como extravagantes e perigosas" isso foram e são perseguidas.

A sociedade burguesa moderna desenvolveu os mecanismos de controle com o objetivo de manter o domínio político e econômico, e, para isso, produziu a docilidade e a obediência dos corpos, desencadeando em um controle geral nomeado por Foucault de "biopoder"1". O capitalismo crescente se valeu desse biopoder para assegurar a dominação de uns sobre outros, em conformidade com as instâncias legais. (FOUCAULT, 1988). Foi por meio do biopoder que se regularam a vida e a vontade das pessoas no tocante ao sexo e à sexualidade, possibilitando a constituição de uma teoria geral do sexo.

A nosso ver, a "teoria geral do sexo facilitou a propagação de um entendimento equivocado da sexualidade"12, provocando múltiplas formas de opressão que produziram, e ainda produzem, profundas marcas aos que não estão de acordo como a sexualidade que é tida como normal.

\footnotetext{
FOUCAULT, 2001, p. 213.

REZENDE, op. cit., p. 40.

FOUCAULT, 1988, p. 132.

12 REZENDE, op. cit., p. 44.
}

De acordo com os estudos de Marilena Chauí (1984), em seu livro Repressão sexual essa nossa (des)conhecida, a repressão sexual não tem uma dimensão universal, pois varia de acordo com o tempo, o espaço, as condições históricas e sociais e, por isso, o mais importante é compreender "[...] sobre quais aspectos da sexualidade recai a repressão [...]"13. Em outras palavras, compreender alguns aspectos culturais, sociais e econômicos do fenômeno da repressão sexual produzidos em uma sociedade capitalista ${ }^{14}$.

[...] Numa sociedade que considera o sexo apenas sob o prisma da reprodução da espécie, ou como função biológica procriadora, serão reprimidas todas as atividades sexuais em que o sexo genital for praticado sem cumprir aquela função: masturbação ou onanismo, homossexualismo masculino e feminino (ou sodomia), sexo oral (felácio, cunilíngua), sexo anal, coito interrompido, polução sem penetração (voyeurismo). Também são reprimidas as práticas que possam perturbar as finalidades atribuídas à procriação. ${ }^{15}$

Na sociedade moderna burguesa, fundamentada na religião cristã, foram reprimidas as práticas sexuais que não estavam a serviço da procriação e decretaram-se as práticas heterossexuais como naturais, fomentando no passado e no presente - o crescimento do preconceito em relação aos que não vivem de acordo com essa normatização.

\footnotetext{
CHAUÍ, 1984, p. 27.

14 Segundo PADILHA e OLIVEIRA (2013), sociedade capitalista refere-se a uma sociedade mercantil, dividida em classes sociais distintas que são marcadas pela alienação. Uma sociedade marcada pelo domínio de grupos hegemônicos, que orientam o rumo das diversas instituições, a fim de garantir a disseminação de ideias e valores que lhes permitam a hegemonia e manutenção do poder. Uma sociedade que historicamente cria e rege a divisão social do trabalho e que separa o trabalho do capital.

15 CHAUÍ, op. cit., p. 77-78.
} 


\section{SOBRE O PRECONCEITO}

Agnes Heller (1970), filósofa húngara, propôs uma análise sobre o preconceito relacionando-o com a vida cotidiana. Segundo a autora é na cotidianidade que tudo acontece; que se desenvolvem todas as nossas manifestações humanas; que organizamos o nosso estar no mundo.

A vida cotidiana se constitui em torno de duas categorias fundamentais: a heterogeneidade e a hierarquia. A heterogeneidade refere-se ao conteúdo e significação presentes na cotidianidade, ou seja, as múltiplas particularidades que compreendem diferentes atividades por nós desenvolvidas. Já a hierarquia relaciona-se com as estruturas econômico-sociais que se constituem em torno da organização da vida. As duas categorias ocorrem simultaneamente justificando e legitimando as diferenças sociais que se manifestam em nosso cotidiano.

Nascemos inseridos na cotidianidade e, na medida em que vamos crescendo, apropriamo-nos dos valores, costumes e normas sociais desenvolvidas pelo grupo ao qual pertencemos, sem questionar sua validade. Essa apropriação ocorre, ao mesmo tempo, de forma particular e genérica em cada indivíduo, de modo que todo sujeito carrega em si as dimensões de particularidade e de genericidade humana.

Ao assumirmos como dadas as funções da vida cotidiana, não refletindo sobre elas, contribuímos com a dimensão particular que se mantém sobre a dimensão humano-genérica, conservando, assim, a lógica baseada na satisfação dos interesses pessoais e no individualismo.

A superação da dimensão particular se realizaria parcialmente, quando as escolhas estivessem pautadas pelas exigências e normas da ética, pela motivação interior para essa inversão. Porém, certa elevação da vida cotidiana só ocorre por meio da arte e da ciência, quando se produzem objetivações mais duradouras, que rompem de certa forma com uma tendência à espontaneidade, que é característica dominante da vida cotidiana. Ressalta-se que mesmo nas esferas da ciência e da arte também se produziu estereótipos que, por sua vez, foram base para preconceitos. Lembremos que a ciência sobre a sexualidade a ciência produziu conhecimentos dessa natureza.

As tarefas diárias são realizadas de acordo com a espontaneidade, pois refletir sobre todas as atividades cotidianas desenvolvidas seria inviável para a realização da vida humana em sociedade. (HELLER, 1970). Por esse motivo é que a maioria dos homens não atinge uma elevação ao humano genérico, permanecendo na dimensão particular-individual tão característica da vida cotidiana.

A pensadora húngara (1970) descreve em seus estudos algumas características que marcam a vida cotidiana, tais como: a probabilidade, a economia, o pragmatismo, a imitação e a ultrageneralização. É nessa última que se formam os juízos provisórios. Os juízos provisórios falsos, quando baseados na fé, se cristalizam em preconceitos e se transformam em verdades, causando grandes dores e tragédias na vida dos sujeitos que se tornam seu alvo, entre eles os sujeitos homossexuais.

Além dos estudos de Heller, encontramos outros elementos para a reflexão sobre o preconceito em José Leon Crochík, psicólogo social da Teoria Crítica, que tem se dedicado à compreensão do fenômeno.

De acordo com o autor,

[...] Aquilo que permite ao indivíduo se constituir é também responsável por ele desenvolver ou não preconceitos. A sua manifestação é individual, assim como responde às necessidades irracionais do indivíduo, mas surge no processo de socialização como resposta aos conflitos aí então gerados. ${ }^{16}$

Aprender a ser preconceituosos surge sempre como uma possibilidade no processo de socialização, podendo também se revelar

\footnotetext{
6 CROCHÍK, 2011, p. 13.
} 
quando queremos negar em nós mesmos o que é revelado pelos outros.

As ideias preconceituosas escondem fatores ideológicos, econômicos, psíquicos, religiosos que se justificam pelo desejo de poder e dominação de uns sobre outros. Nas palavras do Crochík, "a dominação [é] componente constante do preconceito" ${ }^{17}$.

Refletir sobre os fatores econômicos, culturais e ideológicos que são produzidos em uma sociedade capitalista e que se pautam no individualismo e na superioridade de uns sobre outros pode ser o primeiro passo para a diminuição da opressão, da violência e do preconceito.

Sabemos que a constituição da identidade do indivíduo foi permeada pela racionalidade, e que, na sociedade capitalista, é medida pelo valor de mercado e pela produtividade, de modo que cada indivíduo passou a defender os seus próprios interesses aumentando o preconceito. Em outras palavras, na sociedade capitalista somos categorizados, é necessário haver o mais forte e para isso alguns precisam ser diminuídos e desprezados.

Essa categorização se estende aos preconceitos sexuais, constituindo a hierarquia sexual, em que a heterossexualidade ocupou o topo.

De acordo com Daniel Borrillo, a homofobia, o sexismo e o heterossexismo evocam constantemente "a superioridade biológica e moral dos comportamentos heterossexuais"18. Colocando a heterossexualidade no lugar de sexualidade correta e normal, todos os que não se enquadram nessa normatização acabaram de uma forma ou de outra sendo vítimas de duras agressões. Agressões que deveriam ser denunciadas com o mesmo rigor quanto a xenofobia, o racismo e o antissemitismo, a fim de que não assumam as mesmas formas brutais de violência praticadas anteriormente na história.

A discriminação contra homossexuais é perpetuada na forma de interiorização dessa violência, pois crescemos em meio a institui-

17 CROCHÍK, 2011, p. 27.

18 BORRILLO, 2010, p. 30. ções e entre relações sociais que demonstram amplamente a supremacia e a naturalização da heterossexualidade e a hostilidade em relação aos homossexuais.

\section{CONSIDERAÇÕES FINAIS}

Os estudos possibilitaram uma análise mais atenta acerca de alguns elementos históricos e culturais constitutivos da homofobia. Esses elementos revelaram que a homofobia se constitui em oposição à heteronormatividade, que considera a heterossexualidade como norma e referência para as demais sexualidades. Referência que se consolidou diante do silenciamento histórico acerca do processo de constituição familiar, passando pela família consanguínea, punaluana, sindiásmica, até chegar à monogâmica. Tratar a família monogâmica como se ela sempre tivesse existido, desde os tempos remotos, dando-lhes aspecto de natural, esconde que sua formação foi resultado de um processo social que teve sua gênese na divisão sexual do trabalho.

Ocultar dados históricos atende a quais interesses? Parece-nos que esse ocultamento atende aos interesses de dominação de um grupo social sobre outro, tão frequente em uma sociedade dividida em classes.

Lembremos que, ao se referir ao aspecto sexual, a dominação se sustenta na hierarquia da sexualidade, que tem como referência a prática sexual fundamentada na função biológica (macho/ fêmea), em que o macho/ o homem se mantém no topo.

Essa construção histórico-social, baseada na superioridade masculina e no casamento monogâmico, fortaleceu a concepção machista, heterossexista e homofóbica.

Além disso, a busca de saber sobre o sexo, que ocorreu durante o século XIX, também contribuiu para a constituição da homofobia, pois, ao mesmo tempo em que se produziu um conhecimento sobre o sexo, gerou-se, em igual medida, uma normatização da sexualidade.

A normatização da sexualidade produziu e ainda produz duras perseguições, agres- 
sões e preconceitos contra aqueles que se desviam da norma, e entre eles estão os homossexuais.

Como vimos anteriormente, os preconceitos estão presentes na vida cotidiana e servem como juízos provisórios para orientar o nosso estar no mundo, porém, na maioria das vezes não conseguimos modificar esses juízos, que se cristalizam em preconceitos. Além disso, os preconceitos escondem ideias, valores e medos que se encontram na esfera do não consciente e que são frutos das relações sociais e da cultura.

São inúmeros os fatores que constituem o preconceito contra os homossexuais. Conhecê-los é um primeiro passo para a sua superação. Presumimos que se esse conhecimento se estender aos espaços escolares, possibilitando aos alunos a compreensão acerca da genericidade humana, talvez possamos um dia superar o antagonismo de classes, a homofobia e toda forma de preconceito.

\section{REFERÊNCIAS}

ARIĖS, P. História social da criança e da família. Rio de Janeiro: LTC, 1981.

BORRILLO, D. Homofobia: história e crítica de um preconceito. Trad. Guilherme João de Freitas Teixeira. Belo Horizonte: Autêntica, 2010.

CHAUÍ, M. Repressão sexual, essa nossa (des)conhecida. São Paulo: Editora Brasiliense, 1984.

DIAS, M.B. “Legislação brasileira e homofobia”. In: VENTURI, G.; BOKANY, V. (orgs.) Diversidade sexual e homofobia no Brasil. São Paulo: Editora Fundação Perseu Abramo, 2011. p. 163-174.

DINIS, N.F. Educação, relações de gênero e diversidade sexual. Educ. Soc., Campinas, v. 29, n. 103, p. 477-492, maio/ ago. 2008.

CROCHÍK, J.L. Preconceito, indivíduo e cultura. São Paulo: Casa do Psicólogo, 2011.

ENGELS, F. A origem da família, da propriedade privada e do Estado. São Paulo: Centauro, 2002.

FOUCAULT, M. História da sexualidade I: a vontade de saber. Trad. Maria Thereza da Costa Albuquerque e J. A. Guillhon Albuquerque. 10. ed. Rio de Janeiro: Edições Graal, 1998.

. Os anormais: curso no Collège de France (1974-1975). São Paulo: Martins Fontes, 2001.

HELLER, A. O cotidiano e a História. São Paulo: Paz e Terra, 1970.

MARX, K.; ENGELS, F. A ideologia alemã. Introdução de Jacob Gorender. Trad. Luis Cláudio de Castro e Costa. 3 ed. São Paulo: Martins Fontes, 2002.

PADILHA, A.M.L.; OLIVEIRA, I.M. (orgs.): Educação para todos: as muitas faces da inclusão escolar. Campinas: Papirus, 2013.

PINTO, A.D.C.; MENEGHEL, S.N.; MARQUES, A. P. M. K. Acorda Raimundo! Homens discutindo violências e masculinidade. Psico. [on-line] v. 38, n. 3, p. 238-245. Rio Grande do Sul, 2007. Disponível em: <http://revistaseletronicas.pucrs.br/ojs/ index.php/revistapsico/article/view/2885/2180> Acesso em: 14 set. 2015. ISSN 0103-5371.

REZENDE, M.M. A homofobia para além das aparências. 2015. 174 f. Dissertação (Mestrado em Educação). Universidade Metodista de Piracicaba. Piracicaba, 2015. 


\section{DADOS DOS AUTORES}

\section{Marcelo Martins Rezende}

Mestre em Educação pela Universidade Metodista de Piracicaba (UNIMEP). Membro do grupo de pesquisa Práticas educativas e relações sociais no espaço escolar e não escolar (UNIMEP). Piracicaba/SP - Brasil.rezendemm@ig.com.br

\section{Anna Maria lunardi Padilha}

Doutora em Educação, Conhecimento, Linguagem e Arte pela Universidade Estadual de Campinas. Professora do Programa de Pós-graduação em Educação da Universidade Metodista de Piracicaba.Piracicaba/SP - Brasil. anapadi@terra.com.br

Submetido em: 11-10-2015

Aceito em: 18-2-2016 